ORIGINAL ARTICLE

\title{
Use of humour in primary care: different perceptions among patients and physicians
}

\author{
M Granek-Catarivas, S Goldstein-Ferber, Y Azuri, S Vinker, E Kahan
}

Postgrad Med J 2005;81:126-130. doi: 10.1136/pgmj.2004.019406

See end of article for authors' affiliations

.....................

Correspondence to: Dr E Kahan, 7 Arazim Street, no 4, Kfar Sava 44456, Israel; ekahan@ post.tau.ac.il

Submitted 19 January 2004 Accepted 14 April 2004

\begin{abstract}
Purpose: (1) To explore the frequency with which humorous behaviour and statements occur in family medicine practice in Israel, and (2) to quantitatively assess the correlation between the subjective perceptions of humour in medical encounters between patients and physicians.

Method: In a cross sectional study, two populations (doctors and patients) were surveyed with paired structured questionnaires completed immediately after primary care practice visits. Two hundred and fifty consecutive encounters from 15 practices were sampled. The physician questionnaire was self administered, and patient questionnaire was administered by a trained research assistant.

Results: A mean of 16.7 questionnaires was completed per physician (range 6-20). The physicians reported having used some humour in only 95 encounters $(38 \%)$, whereas almost $60 \%$ of patients agreed with the statement, "The doctor used some humour during the visit". At the same time, for specific encounters, the agreement between patients' perception and physicians' perceptions on the use of humour, although not completely by chance $(p=0.04)$, is low $(\kappa=0.115)$. Patient characteristics (age, education, gender, family status, mother tongue, self perceived heath status, stress, mood, and expectations) were not related to the degree of agreement between the patients' and physicians' perceptions.

Conclusion: Humour was used in a large proportion of encounters, independently of patient characteristics. Patients seem to be more sensitised to humour than physicians, probably because of their high stress level during medical encounters. Cultural differences may also play a part. Physicians should be made aware of this magnifying effect, and the issue should be discussed in medical schools.
\end{abstract}

$\mathrm{H}$ umour is being slowly recognised as a useful therapeutic tool in primary care. ${ }^{12}$ Positive psychological and physiological responses to laughter have been shown in a variety of settings, and include stress hormone reduction, mood improvement, increased creativity, pain reduction, improvement in immunity, and reduction in blood pressure..$^{3-5}$ Neurophysiological studies found that viewing a humorous video significantly reduced allergen induced wheal reactions ${ }^{6}$ and decreased saliva cortisol, ${ }^{7}$ and that mirthful laughter reduced serum concentrations of cortisol, dopamine, adrenaline (epinephrine), and growth hormone. ${ }^{8}$ These biochemical changes have implications for the reversal of the neuroendocrine and classic stress hormone response. ${ }^{8}$

Today, humour is considered part of the arousal state, which combined with relaxation and stress reduction, leads to a positive affect and ego strengthening and is positively correlated with health outcomes. ${ }^{9-11}$

In patients, humour can be particularly helpful in lowering anxiety, improving cognitive functioning, and easing coping strategies with pain and stress. ${ }^{12}$ For physicians, humour helps narrow interpersonal and cultural gaps, communicate difficult messages, express frustration and anger, and cope with anxiety. ${ }^{13-15}$ One study found that doctors without malpractice claims are characterised by a sense of humour. ${ }^{16}$ Indeed, hospital departments worldwide now employ clowns for the benefit of patients, their families, and healthcare professionals. ${ }^{17}$

When a positive attitude is shared by patient and physician, it has a favourable effect on both emotional-affective and cognitive functioning and facilitates the introduction of new options and the encounter with curative challenges. However, when one party is defensive or angry, he or she may find humour in the other party offensive or insulting. ${ }^{18}{ }^{19}$ Furthermore, humour can be perceived differently by different people; Hampes ${ }^{20}$ found that there is a relation between humour and both emotional self awareness and emotional intelligence. According to communication theories, humour is a coded message that is deliverable verbally or non-verbally. The receiver interprets the message according to environmental and situational characteristics and their subjective understanding. The process of coding and decoding the message predicts the accuracy of the communication and its effect. ${ }^{21}$

The aims of this study were twofold: (1) to explore the frequency with which humorous behaviour and statements occur in family medicine practice in Israel; and (2) to quantitatively assess the correlation between the subjective perceptions of humour in medical encounters between patients and physicians.

\section{METHODS}

A multicentre cross sectional survey design was used in two populations, primary care physicians and their patients.

\section{Setting/populations}

Fifteen public primary care practices belonging to the largest of the four health maintenance organisations in Israel were selected for the study. All practices were located in the central area of the country where the socioeconomic scale is well distributed. One salaried general practitioner or family physician from each practice was enrolled; all were unaware of the study design.

Patients who regularly attended these practices were included in the study consecutively, according to the list of scheduled appointments during one working session (maximum, 20 patients per physician). First time patients, unscheduled patients, and patients who were younger than 18 years or spoke a language incompatible with their 
Table 1 Patients' agreement with description of encounters

\begin{tabular}{|c|c|c|c|c|c|c|c|}
\hline $\begin{array}{l}\text { Item } \\
\text { number }\end{array}$ & Statement about humorous activities & $\begin{array}{l}\text { Total } \\
\text { number }\end{array}$ & $\begin{array}{l}\text { Agree and } \\
\text { completely } \\
\text { agree (\%) }\end{array}$ & $\begin{array}{l}\text { Completely } \\
\text { agree }(\%)\end{array}$ & Agree (\%) & $\begin{array}{l}\text { Disagree } \\
\text { somewhat (\%) }\end{array}$ & $\begin{array}{l}\text { Completely } \\
\text { disagree (\%) }\end{array}$ \\
\hline 1 & The doctor used humour in this visit & 245 & 60.4 & 29.8 & 30.6 & 11.4 & 28.2 \\
\hline 2 & The doctor said something humorous about me & 239 & 19.7 & 10.0 & 9.6 & 10.5 & 69.9 \\
\hline 3 & $\begin{array}{l}\text { The doctor said something humorous about him/ } \\
\text { herself }\end{array}$ & 239 & 9.6 & 4.2 & 5.4 & 11.7 & 78.7 \\
\hline 4 & The doctor told a joke & 235 & 9.8 & 5.5 & 4.3 & 11.5 & 78.7 \\
\hline 5 & $\begin{array}{l}\text { The doctor did not exhibit any humorous manner } \\
\text { or expression }\end{array}$ & 234 & 28.6 & 10.7 & 17.9 & 21.4 & 50.0 \\
\hline 6 & The doctor did not use humour, we just laughed & 234 & 47.9 & 21.8 & 26.1 & 14.1 & 38.0 \\
\hline 7 & Only the doctor laughed, I did not & 233 & 5.6 & 3.0 & 2.6 & 11.6 & 82.8 \\
\hline 8 & The doctor said only serious things to me & 240 & 72.1 & 52.9 & 19.2 & 18.8 & 9.2 \\
\hline 9 & $\begin{array}{l}\text { The doctor said a cynical or provocative sentence } \\
\text { that made me laugh }\end{array}$ & 235 & 7.7 & 2.6 & 5.1 & 6.0 & 86.4 \\
\hline 10 & $\begin{array}{l}\text { I didn't hear anything humorous from the doctor } \\
\text { today }\end{array}$ & 236 & 33.9 & 20.8 & 13.1 & 23.7 & 42.4 \\
\hline 11 & $\begin{array}{l}\text { I laughed, but not because of anything humorous } \\
\text { the doctor said }\end{array}$ & 233 & 34.8 & 15.5 & 19.3 & 16.3 & 48.9 \\
\hline 12 & $\begin{array}{l}\text { I laughed because the doctor made some funny } \\
\text { faces }\end{array}$ & 236 & 4.2 & 0.8 & 3.4 & 10.2 & 85.6 \\
\hline 13 & We just laughed for no particular reason & 233 & 44.2 & 19.3 & 24.9 & 14.2 & 41.6 \\
\hline 14 & We didn't laugh, it was a serious encounter & 237 & 59.9 & 39.2 & 20.3 & 18.1 & 21.9 \\
\hline
\end{tabular}

physician's were excluded, as were patients who refused to participate. First time patients were excluded on the assumption that patients and physicians with some previous knowledge of each other will behave in a more natural and relaxed manner.

\section{Survey instruments}

Two structured questionnaires were used, one for physicians and one for patients. Each was completed after the encounter, on an anonymous basis; the questionnaires were then paired for analysis. The first item in the physicians' questionnaire, which was completed by the participants themselves, consisted of the question: "Was humour used during the encounter you just had with this patient?" If the answer was yes, the physician was then asked to respond (yes/no) to a series of items regarding the nature and type of the humour used. The patients' questionnaire was developed and modified several times during two pilot studies with a focus group of family physicians and a feasibility study. It was completed in the waiting room by a trained research assistant who interviewed each patient after the visit. The first few items covered background variables and questions about the patient's feelings of wellbeing, stress, and depression, and mental attitude. The patients were then asked whether the doctor had used humour, and if yes, to indicate (yes/no) the degree to which they agreed with a series of statements concerning the nature and type of humour used, which corresponded to the items in the physicians' questionnaire. Examples of the statements in the patient questionnaire were: "The doctor said something humorous about me", or "I laughed but not because of something humorous the doctor said". No free text comments were included in either questionnaire.

\section{Sample size calculation}

Our preliminary pilot studies with two physicians using simpler drafts of the questionnaire showed that there was some form of humour in up to $50 \%$ of the encounters. This finding was used to calculate the minimum sample needed with a confidence level of $95 \%$ and an absolute precision of 10 points from the true proportion (from $40 \%$ to $60 \%$ ). As the anticipated proportion of $50 \%$ was coincident with the "safest choice", our calculated sample size was based on 96 encounters. We then increased this number by $200 \%$ in case of problems with participation or response. Furthermore, a larger population would allow for the consideration of additional variables in the analysis. The final sample size was based on 300 encounters.

\section{Data analysis}

The study questionnaires were checked for completeness, internal logic, and consistency using the $\kappa$ statistic for concordance. All calculations were made after removal of missing data (about 5\% missing responses to a few questions). The physicians' demographic data were not included in the statistical analysis because of their small number. Survey responses were analysed with the SPSSWIN, version $9.01 \mathrm{~b}$. Categorical variables were compared by $\chi^{2}$ or Fisher's exact test, and continuous data with a non-normal distribution were compared by analysis of variance with repeated measures and paired two tailed $t$ test. A p value of 0.05 defined the significance of differences between groups.

\section{RESULTS}

The physicians returned a total of 251 completed questionnaires, of which one was excluded because the patient had not completed his questionnaire after the encounter, for a mean of 16.7 encounters (range 6 to 20) per physician. Another five questionnaires were excluded because the patients failed to answer item 1 (table 1 ).

The final study group consisted of $42 \%$ male and $58 \%$ female patients, of whom $42.9 \%$ spoke Hebrew as their mother tongue, $20.0 \%$ spoke Arabic, and $37.1 \%$ used other languages. Table 2 describes the patients' characteristics.

To evaluate the internal validity of the patients' questionnaire (table 1), we checked the concordance between answers to statements bearing a common meaning: between item 10, "I didn't hear anything humorous from the doctor today" and item 14, "We didn't laugh, it was a serious encounter" ( $\kappa=0.38, \mathrm{p}<0.001)$; between item 8 , "The doctor said only serious things to me" and item 14, "We didn't laugh, it was a serious encounter" $(\kappa=-0.44, \mathrm{p}<0.001)$; between item 6 , "The doctor didn't use humour, we just both laughed" and item 13 "We just laughed for no particular reason" $(\kappa=0.66, \mathrm{p}<0.001)$. The results show that similar questions received similar values. We therefore assumed that the responders understood their meaning. The physicians reported that they used some humour in 95 of the 250 
Table 2 Patients' characteristics by agreement with physicians' report concerning humour

\begin{tabular}{|c|c|c|c|c|c|}
\hline Patient characteristics & Agree & & Do not agree & & Total \\
\hline Age $(y)$ : mean (SD) & $50.4(18.0$ & & $50.9(18.4)$ & & $50.6(18.1)$ \\
\hline Education $(y)$ : mean (SD) & $11.7(4.3)$ & & $11.5(4.3)$ & & $11.6(4.3)$ \\
\hline Sex & Number & $\%$ & Number & $\%$ & Number \\
\hline Male & 53 & 58.2 & 38 & 41.8 & 91 \\
\hline Female & 78 & 50.6 & 76 & 49.4 & 154 \\
\hline \multicolumn{6}{|l|}{ Family status } \\
\hline 1 Never married & 20 & 58.8 & 14 & 41.2 & 34 \\
\hline 2 Married & 97 & 54.5 & 81 & 45.5 & 178 \\
\hline 3 Widowed & 11 & 47.8 & 12 & 52.2 & 23 \\
\hline 4 Divorced & 3 & 30.0 & 7 & 70.0 & 10 \\
\hline \multicolumn{6}{|l|}{ Mother tongue } \\
\hline 1 Hebrew & 55 & 52.4 & 50 & 47.6 & 105 \\
\hline 2 Arab languages & 28 & 57.1 & 21 & 42.9 & 49 \\
\hline 3 Other & 48 & 52.7 & 43 & 47.3 & 91 \\
\hline \multicolumn{6}{|l|}{ Self perceived health status } \\
\hline 1 Poor & 13 & 65.0 & 7 & 35.0 & 20 \\
\hline 2 Fair & 46 & 52.9 & 41 & 47.1 & 87 \\
\hline 3 Good & 48 & 55.8 & 38 & 44.2 & 86 \\
\hline 4 Excellent & 23 & 46.0 & 27 & 54.0 & 50 \\
\hline \multicolumn{6}{|l|}{$\begin{array}{l}\text { State of mood-tension free } \\
\text { during past month }\end{array}$} \\
\hline 1 All the time & 12 & 52.2 & 11 & 47.8 & 23 \\
\hline 2 Most of the time & 22 & 37.9 & 36 & 62.1 & 58 \\
\hline 3 About half of the time & 27 & 65.9 & 14 & 34.1 & 41 \\
\hline 4 Some of the time & 26 & 60.5 & 17 & 39.5 & 43 \\
\hline 5 Little time & 26 & 53.1 & 23 & 46.9 & 39 \\
\hline 6 Not at all & 15 & 53.6 & 13 & 46.4 & 28 \\
\hline \multicolumn{6}{|l|}{$\begin{array}{l}\text { State of mood-lack of hope } \\
\text { during past month }\end{array}$} \\
\hline 1 All the time & 8 & 72.7 & 3 & 27.3 & 11 \\
\hline 2 Most of the time & 9 & 47.4 & 10 & 52.6 & 19 \\
\hline 3 About half of the time & 11 & 68.8 & 5 & 31.3 & 16 \\
\hline 4 Some of the time & 17 & 47.2 & 19 & 52.8 & 36 \\
\hline 5 Little time & 32 & 50.0 & 32 & 50.0 & 64 \\
\hline 6 Not at all & 78 & 78.0 & 22 & 22.0 & 100 \\
\hline \multicolumn{6}{|c|}{$\begin{array}{l}\text { Today, how much have you hoped } \\
\text { for a pleasant day? }\end{array}$} \\
\hline 1 All the time & 27 & 54.0 & 23 & 46.0 & 50 \\
\hline 2 Most of the time & 28 & 51.9 & 26 & 48.1 & 54 \\
\hline 3 About half of the time & 20 & 58.8 & 14 & 41.2 & 34 \\
\hline 4 Some of the time & 22 & 47.8 & 24 & 52.2 & 46 \\
\hline 5 Little time & 23 & 54.8 & 19 & 45.2 & 42 \\
\hline 6 Not at all & 11 & 57.9 & 8 & 42.1 & 19 \\
\hline
\end{tabular}

encounters $(38 \%)$. By contrast, almost $60 \%$ of the patients reported that the use of humour existed in their encounters; this difference was significant $(\mathrm{p}<0.05)$. For item 1 , "The doctor used some humour during the visit", 73 (29.8\%) patients agreed completely and 75 (30.6\%) agreed somewhat; of the remainder, 28 (11.4\%) disagreed somewhat, and 69 $(28.2 \%)$ disagreed completely (table 1 ).

The following is the distribution of patient responses, where the type of humour "used by the physician" was categorised as intentional, spontaneous, no humour, and unclear (table 1):

- Intentional: "The doctor used humour: (item 1) (60.4\% patient agreement), "The doctor said something humorous about me" (item 2) (19.7\% agreement), "The doctor told a joke" (item 4) (9.8\%), "The doctor told me something humorous about himself" (item 3) (9.6\%), "The doctor said a cynical or provocative sentence that

Table 3 Degree of agreement between patients' perceptions and physicians' reports about physicians' use of humour

\begin{tabular}{|c|c|c|c|c|}
\hline & & \multicolumn{3}{|c|}{ Doctors' use of humour: patients' perceptions } \\
\hline \multicolumn{2}{|c|}{ Doctors' use of humour: physicians'reports } & No & Yes & Total \\
\hline \multirow[t]{3}{*}{ No } & count & 68 & 85 & 153 \\
\hline & $\%$ horizontal & 44.4 & 55.6 & 100.0 \\
\hline & $\%$ vertical & 70.1 & 57.4 & 62.4 \\
\hline \multirow[t]{3}{*}{ Yes } & count & 29 & 63 & 92 \\
\hline & $\%$ horizontal & 31.5 & 68.5 & 100.0 \\
\hline & $\%$ vertical & 29.9 & 42.6 & 37.6 \\
\hline \multirow[t]{3}{*}{ Total } & count & 97 & 148 & 245 \\
\hline & $\%$ horizontal & 39.6 & 60.4 & 100.0 \\
\hline & $\%$ vertical & 100 & 100.0 & 100.0 \\
\hline
\end{tabular}


Table 4 Different kinds of humorous activities in physicians' reports

\begin{tabular}{llr}
\hline Humorous activities & Number & \multicolumn{1}{l}{$\%$} \\
\hline Total humorous activities* & 108 & 100.0 \\
I told a joke & 11 & 10.2 \\
I told a funny story & 8 & 7.4 \\
I made a humorous movement & 6 & 6.6 \\
We both broke into laughter & 17 & 15.7 \\
I laughed, but it didn't work & 4 & 3.7 \\
We did nothing, but we both laughed & 30 & 27.8 \\
Something else was humorous & 32 & 19.6 \\
\hline
\end{tabular}

*Mean 1.14 humorous activities per encounter. Total 95 humorous encounters.

made me laugh" (item 9) (7.7\%), and "The doctor made some funny faces" (item 12) (4.2\%).

- Spontaneous: “The doctor didn't use any humour, we just laughed" (item 6) (47.9\% patient agreement), "We both laughed for no particular reason" (item 13) (44.2\%), and "I laughed, but not because of anything humorous the doctor said" (item 11) ((34.8\%).

- No humour: "The doctor said only serious things to me" (item 8) (72.1\%), “We didn't laugh, it was a serious encounter" (item 14) (59.9\%), "I didn't hear anything humorous from the doctor today" (item 10) (33.9\%), and "The doctor didn't show any humorous manner or expression" (item 5) (28.6\%).

- Unclear: "The doctor laughed, but I did not" (5.6\% patient agreement).

At the same time, when the two questionnaires for each encounter were matched, we found that in 131 encounters $(53.5 \%)$, the patients' perceptions were similar to those of their physician and in $114(46.5 \%)$, they differed (table 3$)$. The agreement between patients' perception and physicians' perceptions on the use of humour, although it is not completely by chance $(p=0.04)$, it is rather low $(\kappa=0.115)$. As patient characteristics (age, education, sex, family status, mother tongue, self perceived health status, stress, mood, and expectations) had no significant value in differentiating those who had a similar perception to their physician's from those who did not, the corresponding data are not presented.

Table 4 shows the number of distinct humorous activities in each encounter. According to the physicians' reports, a mean (SD) of 1.14 (0.53) humorous activities (range 1-5) occurred in each of the 95 encounters with humour. Humorous attitudes or movements or just laughter were much more common (89 of 108 activities, $82 \%$ ) than telling jokes or funny stories (19 of 108, 18\%).

\section{DISCUSSION}

This study investigated the perceptions of patients and physicians of humour during medical encounters in general practice. The surveys were entirely subjective and based on the independent perceptions of the physicians and the patients. As such, we did not confirm or quantify the humour according to the parties involved or against a standardised tool. The physicians were given no special instructions and were not informed of the patients' participation in the research protocol. Although some physicians may have modified their behaviour after being told the purpose of the study, we believe this factor was neutralised over time by the large size of the patient sample.

The most interesting finding was the large discrepancy in the rate of patients reporting that the physician had used some humour $(60.4 \%)$ and the rate of physicians reporting that they had not (37.6\%). Apparently, doctors and patients decode messages differently, leading to differences in perception of humour. We speculate that patients tend to be stressed at the beginning of the encounter so that any small humorous message by the doctor has a high relaxation effect, and is therefore perceived as containing a higher level of humour than intended. That is, the patient's decoding process magnifies the doctor's message to achieve or maintain a certain state of relaxation during the encounter. It is also well accepted that people laugh and smile when they are uncomfortable. According to some researchers in the field of communication, "22 "expert power" on the side of the message sender (the doctor) may impair the accuracy of the decoding process by the receiver (the patient). This kind of "psychological noise" has also been observed in other settings, such as dealing with government bureaucracies. ${ }^{23}{ }^{24}$ It is important that doctors be aware of this amplifying effect. Further studies are warranted on the use of humorous messages to patients and their emotional responses.

Concerning the various kinds of humour used by physicians (table 4), it is interesting to note that they reported mostly non-verbal humour. Patients recognised spontaneous humour or laughter more frequently than intentional humour. Despite the highly significant internal consistency of the patients' answers, the high rates of agreement to certain contradictory items show that there must have been some overlap. Nevertheless, for example, $60.4 \%$ of the patients agree that "the doctor used humour in this encounter", but $72.1 \%$ agreed that "The doctor said only serious things to $\mathrm{me}^{\prime}$, and $59.9 \%$ agreed that "We didn't laugh, it was a serious encounter". It is possible, therefore, that some patients do not see a contradiction between the use of humour and the performance of a serious encounter.

Verbal and non-verbal expressions of humour vary with the specific culture and the specific interaction between people. Sometimes humour is clearly generated by one party and received or perceived by the other, and sometimes it just exists as a "virtual ball" bouncing between the two. The only marginally significant degree of agreement between patients and physicians about the presence or absence of humour in each encounter is difficult to explain, especially in view of the discrepancy for the rates at which humour was reported by the two groups. Our analysis yielded no effect of the patients' background characteristics, or of their prior mood or state of mind. The absence of a correlation of background features on patient perception of humour shows that no one patient subgroup could be identified as perceiving the situation differently from all the other patients. This might be explained by our finding that the type of humour most often perceived by the patients was of a non-verbal type, which is probably less dependent on culture, language, or education. In a medical encounter, humour apparently serves as a means or vehicle of communication. By contrast, in books or the theatre, humour is often an aim in itself, and in these cases, cultural similarities would be more important in increasing receptiveness. We assume there are other, unrecognised factors that affect the interpretation of messages on both sides.

The effect of humour on satisfaction or general feeling or other health outcomes was beyond the scope of the study. The literature suggests positive effects. ${ }^{12}$ A higher degree of agreement between physicians' and patients' subjective perceptions could further improve these benefits. If humour is a communication skill, it needs to be further explored and developed as an additional valuable tool in medicine. Physicians' awareness of the usefulness of humour should be increased, and the subject should be taught and tested in medical schools and at an academic level. 


\section{CONCLUSION}

In this study conducted in a primary care setting, humour was present in a large proportion of patient-physician encounters, independent of the patients' characteristics. Humour in these cases is apparently a mode of communication, and it often occurs spontaneously. It is well accepted by the patients, who seem to be more sensitised to it than their physicians, and it does not come at the expense of loss of seriousness. Further research, not only quantitative but also qualitative, is needed to better define the strengths and limitations of the use of humour in the consultation room.

\section{ACKNOWLEDGEMENTS}

This survey is dedicated to the memory of Dr Michael Herz, who developed its original idea and performed the initial pilot survey with Dr Simon Zalewski. We wish to thank the members of the research group of the Department of Family Medicine at Tel Aviv University for their active contribution and support, and the family physicians of the sample for their cooperation.

\section{Authors' affiliations}

M Granek-Catarivas, S Goldstein-Ferber, Y Azuri, S Vinker, E Kahan, Department of Family Medicine, Sackler Faculty of Medicine, Tel Aviv University, Tel Aviv, Israel

Funding: this study was partially supported by a grant from the Clalit Health Services, Israel.

Conflicts of interest: none declared.

\section{REFERENCES}

1 Black DW. Laughter. JAMA 1984;252:2995-8.

2 Wender RC. Humor in medicine. Prim Care 1996;23:141-54.

3 Hassed C. How humor keeps you well. Aust Fam Physician 2001;30:25-8.

4 Lefcourt HM, Thomas S. Humor and stress revisited. The sense of humor: explorations of a personality characteristic. Humor Research 1998;3:179-202
5 Newman MG, Stone AA. Does humor moderate the effects of experimentally induced stress? Ann Behav Med 1996;18:101-9.

6 Kimata $\mathrm{H}$. Effect of humor on allergen-induced wheal reactions. JAMA 2001;285:738.

7 Buchanan TW, al'Absi M, Lovallo WR. Cortisol fluctuates with increases and decreases in negative affect. Psychoneuroendocrinology 1999;24:227-41.

8 Berk LS, Tan SA, Fry WF, et al. Neuroendocrine and stress hormone changes during mirthful laughter. Am J Med Sci 1989;298:390-6.

9 Witztum E, Briskin S, Lerner V. The use of humor with chronic schizophrenic patients. J Contemporary Psychother 1999;29:223-34.

10 Wright $\mathbf{F}$. The use of the self in group leadership: a rational perspective. Int J Group Psychother 2000;50:181-98.

11 Yonkovitz E, Matthews WJ. The potential for strategic therapeutic humor in fostering self-observation: using both retrospective and concurrent client amusement. Journal of Systematic Therapy 1998;17:45-57.

12 Tyson PD. Physiological arousal, reactive aggression and the induction of an incompatible relaxation response. Aggression and Violent Behavior 1998;3:143-58.

13 Beck RS, Daughtridge R, Sloane PD. Physician-patient communication in the primary care office: a systematic review. J Am Board Fam Pract 2002; 15:25-38.

14 Ackerman MH, Henry MB, Graham KM, et al. Humor won, humor too: a model to incorporation humor into the health care setting. Nurs Forum 1994:29:15-21.

15 Yates $\mathbf{S}$. Finding your funny bone. Incorporating humor into medical practice. Aust Fam Physician 2001;30:22-4.

16 Levinson W, Roter DL, Mullooly JP, et al. Physician-patient communication. The relationship with malpractice among primary care physicians and surgeons. JAMA 1997;277:553-9.

17 Spitzer P. The clown doctors. Aust Fam Physician 2001;30:12-16.

18 Rosenheim E, Golan G. Patients' reactions to humorous interventions in psychotherapy. Am J Psychother 1986;40:11-24.

19 Epstein BH. The use of humor in cognitive-behavioral therapy with outpatient depressed male adolescents. The Sciences and Engineering 1997;57(9B):5915.

20 Hampes WP. Relationship between humor and emphatic concern. Psychol Rep 2001;88:241-4.

21 Defleur ML, Dennis EE. Understanding mass communication. New York: Houghton Mifflin, 1998.

22 Burgoon M, Frank FG, Dawson EF. Human communication. Thousand Oaks, CA: Sage, 1994

23 Weinmann G. Dealing with bureaucracy: the effectiveness of different persuasive appeals. Soc Psychol Q 1982;45:136-44.

24 Weinmann G. Sex differences in dealing with bureaucracy. Sex Roles 1985; 12:777-90. 